
\title{
\& Research Square \\ Bioavailability of Inhaled Or Ingested PFOA Adsorbed To House Dust
}

\author{
Åsa Maria Gustafsson ( $\nabla$ asamgus@gmail.com ) \\ Örebro University https://orcid.org/0000-0001-6765-3848 \\ Bei Wang \\ Örebro University \\ Per Gerde \\ Karolinska Institutet \\ Åke Bergman \\ Örebro University \\ Leo W. Y. Yeung \\ Örebro University
}

\section{Research Article}

Keywords: Perfluorooctanoic acid, household dust, ingestion, gastro intestinal (GI), airways, adsorption, PFAS

Posted Date: January 6th, 2022

DOI: https://doi.org/10.21203/rs.3.rs-1134800/v1

License: (c) (i) This work is licensed under a Creative Commons Attribution 4.0 International License.

Read Full License 


\section{Abstract}

Indoor environments may impact human health due to chemical pollutants in the indoor air and house dust. This study aimed at comparing the bioavailability and distribution of PFOA following both an inhalation and an oral exposure to PFOA coated house dust in rats. In addition, extractable organofluorine (EOF) was measured in different tissue samples to assess any potential influence of other organofluorine compounds in the experimental house dust. Blood samples were collected at sequential time points after exposure and at the time of termination; lung, liver and kidney were collected for quantification of PFOA and EOF. The concentration of PFOA in plasma increased rapidly in both exposure groups attaining a $\mathrm{C}_{\max }$ at $3 \mathrm{~h}$ post exposure. The $\mathrm{C}_{\max }$ following inhalation was four times higher compared to oral exposures. At $48 \mathrm{~h}$ post exposure, the levels of PFOA in plasma, liver and kidney were twice as high from inhalation exposures. This shows that PFOA is readily bioavailable and has a rapid systemic distribution following an inhalation- or oral exposure to house dust coated with PFOA. The proportion of PFOA to EOF corresponded to approximately $54-68 \%$ and $>80 \%$ in plasma and tissues, respectively. The mass balance between EOF and target PFOA indicate that there might be other unknown PFAS precursor and/or fluorinated compounds that co-existed in the house dust sample that might have accumulated in rats.

\section{Introduction}

Perfluorooctanoic acid (PFOA) belongs to the large group of per- and polyfluoroalkyl substances (PFAS) which include more than 4700 substances (OECD 2018; Wang et al. 2017). Due to the unique properties of PFAS being both water and grease repellent, they have been used in numerous industrial- and commercial products (DeWitt et al. 2019). Most PFAS, including PFOA, are extremely resistant to any chemical-, physical- or biological transformations; they are highly persistent and ubiquitously found in different environmental compartments (Buck et al. 2011; De Silva et al. 2021). Higher bio-accumulative potentials were observed for those PFAS having more than five fluorinated carbon for sulfonates and more than seven fluorinated carbon for carboxylates (DeWitt et al. 2019; Stahl et al. 2011).

The bioavailability of PFOA, crossing biological barriers, is indicated by the detection of PFOA in blood and mothers' milk samples (Awad et al. 2020; Calafat et al. 2007; Tao et al. 2008; Völkel et al. 2008; Ye et al. 2018). The major route of exposure to PFOA in humans comes from ingestion of contaminated food and drinking water (Hu et al. 2019; Sadia et al. 2020; Stahl et al. 2011; Trudel et al. 2008). In addition, other exposure pathways to PFOA have been identified via indoor air and dust through inhalation, ingestion and dermal uptake (Salthammer et al. 2018). Haug and colleagues demonstrated that the indoor environment is an important factor of human exposure to PFAS like PFOA (Haug et al. 2011a). PFOA and its derivatives are found in consumer products like e.g. carpets and furnishing, cookware, food papers and clothing (Egeghy and Lorber 2011; Goosey and Harrad. 2011; Verner et al. 2015). The presence of PFOA on house dust is ubiquitous from all over the world (Björklund et al. 2009; Byrne et al. 2017; D'Hollander et al. 2010; Eriksson and Kärrman 2015; Gustafsson et al. manuscript in prep.; Goosey and Harrad 2011; Haug et al. 2011b; Huber et al. 2011; Kato et al. 2009; Knobeloch et al. 2012; Kubwabo et al. 2005; Moriwaki et al. 2003; Schoeib et al. 2016; Xu et al. 2013; Tian et al. 2016; Weiss et al. 2021; 
and Winkens et al. 2018). Considering that PFAS are extensively used in indoor products and owing to the long time that we spend indoors daily (approximately 90\%), it is of great importance to determine the bioavailability of PFOA from house dust via relevant exposure pathways. The bioavailability over the airblood-barrier following inhalation of aerosolized PFOA to rats has indicated on a high uptake over the airways (Hinderliter et al. 2006). Also, the absorption of PFOA (ammonium salt: APFO) following an oral exposure in animal studies showed that virtually all of it was absorbed over the gastrointestinal tract (GI) (DeWitt. 2015). The investigation of the bioavailability of PFOA from inhaled house dust have to our knowledge never been reported before.

Fluorine mass balance analysis between extractable organofluorine (EOF) and quantified PFAS has been used to indicate the presence of unidentified organofluorinated compounds (Koch et al. 2019). Current investigation used house dust coated with PFOA for exposure; previous studies showed the presence of different classes of PFAS in indoor house dust (Eriksson and Kärrman 2015; Gustafsson et al. manuscript in prep). Fluorine mass balance analysis in current study may demonstrate the presence of other unidentified PFAS and metabolites as well as conjugated products formed upon exposure.

The objectives of this study were to investigate the bioavailability of PFOA in rats following inhalation or ingestion of house dust. High amounts of PFOA were adsorbed to the surface of a respirable fraction of house dust. A relevant inhalation exposure condition was established by using the Preciselnhale system, where intubated rats inhaled house dust spontaneously. The levels of PFOA were then analysed in plasma at several subsequent time points. The time-kinetic of PFOA levels in the plasma were compared between the inhalation- and oral exposure to house dust. Also, the distribution of PFOA to different tissues were compared between the two exposure pathways. In addition, this study investigated the amounts of unidentified organofluorine compounds in plasma and different tissue compartments.

\section{Materials And Methods}

\section{Chemicals}

The PFOA ( $\geq 98 \%$ ) for dust coating experiments was purchased as solid standard from Sigma Aldrich (St. Louis, MO, USA). Analytical native standard of PFOA (perfluoro-n-octanoic acid), mass-labelled extraction standard served as internal standard (IS), perfluoro-n-[1.2.3.4- 13C4]-octanoic acid), and masslabelled injection standard served as recovery standard (RS), perfluoro-n-[ $\left.{ }^{13} \mathrm{C} 8\right]$-octanoic acid), were purchased from Wellington Laboratories (Guelph, Ontario. Canada). Ammonium acetate, methyl-tert-butyl ether (MTBE) ( $\geq 99.8 \%$ ), tetrabutylammonium bisulfate (TBA) with a purity of $\geq 99 \%$ and methylpiperidine (1-MP, 99\%) were purchased from Sigma-Aldrich ${ }^{\circledR}$ (St. Louis, MO, USA). OASIS ${ }^{\circledR}$ WAX (6 mL, $\left.150 \mathrm{mg}\right)$ was from the Waters Corporation (Milford, MA, USA). Formic acid (>95\%), methanol HPLC-grade ( $\geq 99.8 \%$ ), methanol LC-MS-grade ( $\geq 99.9 \%)$, acetonitrile HPLC-grade $(\geq 8499.9 \%)$ and ammonium solution (25\%) were purchased from Fisher Scientific (Pittsburgh, PA. USA).

Respirable fraction of house dust 
The house dust was obtained from vacuum cleaner bags collected from 32 residential homes in the region of Stockholm, Sweden. The respirable fraction of house dust was retrieved by a sieving process of which all 32 vacuum cleaner bags were pooled. The processing of dust, to a respirable particulate size fraction have been described in detail by Gustafsson et al. 2018 (Gustafsson et al. 2018). Briefly, the dust was sieved through six stages of plane woven steel meshes, followed by passage of a cyclone, after which the dust was collected in a filter bag. The dust was once again sieved through a twilled woven steel, yielding the respirable fraction. The sieving process was performed under constant airflow and mechanical deagglomeration.

Sorption of PFOA on house dust in the gas phase

To achieve a sufficient concentration of PFOA on the house dust, to ensure detectability in the tissue samples, a near saturated vapor concentration procedure was adopted to adsorb/absorb PFOA on the house dust. Ten grams of solid pure perfluorooctanoic acid was placed in a glass jar bottle, capped with a lid, shaken and stored at room temperature $\left(25 \pm 0.1^{\circ} \mathrm{C}\right)$ to allow vaporization and pre-equilibration of PFOA on the walls of the glass jars. Following equilibration of PFOA in the air and on walls of jars, a portion of $5 \pm 0.03 \mathrm{~g}$ dust was placed in a polypropylene (PP) round plate inside each of four jars. These were capped and kept under the controlled room temperature and atmospheric pressure over time, mimicking a residential indoor environment, but with a near saturated vapor of PFOA. Repeated samples of dust were withdrawn from the jars over time and analyzed for the PFOA content. This procedure was repeated over time for up to 6 weeks until a stable equilibrium concentration of PFOA was attained adsorbed to the dust. The long equilibration time in the near saturated gas-phase of PFOA allowed for an even adsorption/absorption on the dust particles in the testbed.

During the adsorption process, the concentration of PFOA adsorbed to the dust was periodically measured after a rotatory mixing of dust samples with a tube rotator or $24 \mathrm{~h}$ prior to the extraction procedures and instrumental analysis. Preliminary trials showed that this rotatory mixing prevented the formation of pockets of condensed PFOA at the outer edges of the sieved dust facing higher air concentrations of PFOA. The procedure resulted in a uniform adsorption over the entire dust sample on the PP plate. Measurements were repeatedly performed until a saturation of PFOA was reached on the dust. At the time when the concentration was within $10 \%$ of the previous measurement the dust was considered as saturated. The dust was stored in a $-20^{\circ} \mathrm{C}$ freezer until the animal exposure experiment. Four replicated dust adsorption tests were prepared identically in this manner to verify the reproducibility of the dust adsorption experiment and homogeneity of the PFOA adsorbed dust samples.

\section{Animals}

This study was conducted in accordance with a protocol approved by the Animal Committee of ethics in Linköping, Sweden according to Directive 2010/64/EU.

Male Rat RccHan:WIST, approximately 22 weeks of age (450 - 575g), were purchased from Envigo, Venray, Netherlands. The rats were housed five each in clear polycarbonate cages $(20 \times 25 \times 47 \mathrm{~cm})$ 
containing enrichment such as nesting material, chew sticks and tunnels. Water from the municipal tap and extruded rodent diet 2016 Teklad global, 16\% protein (Envigo. Venray. Netherlands) were provided ad libitum. Animals were housed in a facility that maintained an average temperature of $23.2^{\circ} \mathrm{C}$ (Min: $21.6-$ Max:23.9), average humidity of 51.1\% (Min:25.4 - Max:60), and a $12 \mathrm{~h}$ light :12 h dark cycle.

\section{Experimental design}

A total of 10 animals were used in the study. Four rats in each group were exposed by either inhalation- or gavage, respectively. Two rats were unexposed and used as experimental control animals. For both exposed groups, the blood samples were collected prior to exposure (0h) and then at 3, 6, 24 and $48 \mathrm{~h}$ post exposure. The blood was kept on ice after collection. Blood samples were collected from the control rats at the time of termination. The blood samples were centrifuged at $2000 \mathrm{~g}$ for $5 \mathrm{~min}$ and the plasma samples were stored at $-20^{\circ} \mathrm{C}$ until the analyses. At the time of termination, $48 \mathrm{~h}$ after exposure, the rats were exsanguinated under isoflurane and oxygen anesthesia. Bronchoalveolar lavage fluid (BALF) was collected with $5 \mathrm{~mL}$ of sodium chloride and stored in a freezer at $-20^{\circ} \mathrm{C}$. The lungs, liver and kidney were removed and frozen in liquid nitrogen followed by freezer storage $\left(-20^{\circ} \mathrm{C}\right)$ until analyses. All plastics that were used were made of PP or high-density polyethylene to avoid loss of PFOA due to adsorption to the plastics.

Aerosol generation and aerodynamic particle size distribution

An aerosol was generated with the Preciselnhale ${ }^{\circledR}$ platform (Inhalation Sciences Sweden AB, Stockholm, Sweden) and particle size distribution of the house dust was measured with a nine-stage Marple cascade impactor (Marple and McCormack, 1983). The dust was aerosolized batch wise into a $300 \mathrm{~mL}$ holding chamber of the Presicelnhale ${ }^{\circledR}$ and then pushed out at a flow rate of $330 \mathrm{~mL} / \mathrm{min}$. Prior to aspiration into the impactor, the aerosol was diluted into a continuous airflow of $2 \mathrm{~L} / \mathrm{min}$. The mass of dust deposited on the nine stages in the impactor were used to calculate the Mass Median Aerodynamic Diameter (MMAD) and the Geometric Standard Deviation (GSD). The method was adapted from Selg and coworkers (Selg et al. 2010; Selg et al. 2013) and the aerodynamic characterization of the respirable fraction of the pooled house dust used in this study has previously been described by Gustafsson et al. 2018 (Gustafsson et al. 2018).

PFOA dust inhalation exposure

The house dust was aerosolized with the DustGun powder generator and then delivered to the rats with the Preciselnhale dispensing system. In order to determine the system settings for reaching the target dose of dust, pre-exposure filter experiments were performed with the Preciselnhale system. The inhaled mass of the dust collected using an in vitro filter test system for rats exposed in vivo by intratracheal intubation, was calibrated against the optical signal from a Casella Microdust Pro light dispersion instrument (Casella CEL, Inc., Buffalo, NY). An inhaled dose of approximately $0.5 \mathrm{mg}$ of dust per animal was decided; to compare to $0.5 \mathrm{mg}$ for the gavage. The achievable dose of $0.5 \mathrm{mg}$ house dust inhaled resulted in a deposited dose of $0.26 \mathrm{mg}$ per rat, based on a calculated deposition fraction of 0.51 as 
determined with the MPPD model for the particle size distribution of the house dust (Asgharian et al. 2002). Because of a time limitation on how long the animals could be kept intubated, the previously achieved deposited dose by gavage could not be fully reached via inhalation. However, for organic inhalants such as PFOA, dose normalization between adjacent exposure levels can be accurately achieved with retained accuracy of the pharmacokinetics (Malmlöf et al., 2019).

The rats were anesthetized by administrating a premedication of $0.05 \mathrm{mg} / \mathrm{mL}$ atropine $(50 \mu \mathrm{g} / \mathrm{kg} \mathrm{bw})$ subcutaneous followed by a cocktail of fentanyl $(10-15 \mu \mathrm{g} / \mathrm{kg} \mathrm{bw})$ and Dormitor Vet. $(0.21-0.30 \mathrm{mg} / \mathrm{kg}$ bw) (50:50) that was administrated gradually in the tail vein intravenous until anesthesia was achieved. The rats were intubated with a stainless-steel catheter (outside diameter $2.02 \mathrm{~mm}$, inside diameter 1.67 $\mathrm{mm}$, length $6 \mathrm{~cm}$ ) using a laryngoscope. The intubated rat was placed on heating pad in supine position on an adjustable table and connected to the Preciselnhale system. Each animal was monitored for 5 minutes before aerosol exposure to ensure stable spontaneous breathing. Four animals were exposed to 9-10 exposure shots of dust during an exposure time of approximately 10 minutes. The generated aerosol was drawn from the aerosol holding chamber past the breathing animal at a superimposed flow rate of $340 \mathrm{~mL} / \mathrm{min}$, which was close to the optimal relation between ventilation rate and the superimposed flow rate for wasting a minimum of test substance, yet preventing rebreathing of exhausted aerosol (Moss et al. 2006). After the inhalation exposure the rats was injected intramuscularly with Naloxon (0.08-0.1 $\mathrm{mg} / \mathrm{kg} \mathrm{bw}$ ) for a fast recovery from anesthesia.

PFOA dust oral gavage exposure

A suspension of $0.5 \mathrm{mg}$ of dust was prepared in $2 \mathrm{~mL}$ tap water. The rats were gavaged by a single dose of dust with PFOA. After the delivery of dust, the tube was rinsed with an additional volume of $1.5 \mathrm{~mL}$ of tap water which was also delivered to the rats.

Chemical analysis

Gas phase PFOA sampling and analysis

The gas phase of PFOA was collected with OSHA Versatile Sampling (OVS) tubes with XAD-2 resin (SKC). Samples were collected at a flowrate of $0.04 \mathrm{~L} / \mathrm{min}$ using vacuum sampling pumps. Collection times were set for 5 min typically for a $200 \mathrm{~mL}$ air sample. PFOA from the OVS sampler was extracted prior to analysis into two fractions with each fraction placed into individual PP tubes. Fraction A consisted of the glass or quartz fiber filter and first section of XAD resin beads and the first polyurethane foam (PUF) filter. Fraction $B$ consisted of the second section of XAD resin beads and the back PUF filter. All samples were spiked with $50 \mu \mathrm{L}$ of $1 \mu \mathrm{g} / \mathrm{mL}$ C13 solution, the surrogate standard. Each section was placed in PP tube to which $5 \mathrm{~mL}$ of HPLC-grade methanol was added. The tube was shaken for $60 \mathrm{~min}$ on a mechanical flatbed shaker set at $\sim 2$ cycles per sec. Approximately $4.5 \mathrm{~mL}$ of each extract was transferred to a prebaked amber glass vial by filtering through a Gelman GHP Acrodisc (Pall Gelman Laboratory, Ann Arbor, $\mathrm{MI}$, USA.). Each extract of consisting of $200 \mu \mathrm{L}$ was transferred to an autosampler vial with PP insert. 
After that, $10 \mu \mathrm{L}$ of recovery standard was added to the autosampler vial for PFAS analysis using LCMS/MS.

\section{Respirable fraction of dust}

Internal standard $(50 \mu \mathrm{L})$ was added to the sieved dust $(50 \mathrm{mg})$ and was left to equilibrate overnight. The sample was extracted with methanol $(2 \mathrm{~mL})$ with $30 \mathrm{sec}$ vortex and $15 \mathrm{~min}$ sonication in-between. The extract was centrifuged (3000 rpm) for $10 \mathrm{~min}$ and the supernatant transferred into a new tube. The procedure was repeated once with methanol $(1 \mathrm{~mL})$. The combined extract for PFOA analysis was cleaned up by diluting it in $25 \mathrm{~mL}$ MilliQ water and the sample was adjusted to $\mathrm{pH} 10$ with ammonium hydroxide. Hexane $(4 \mathrm{~mL})$ was added to the water, separated by centrifugation $(3000 \mathrm{rpm})$ and the hexane phase was discarded. The $\mathrm{pH}$ of the water was adjusted to $\mathrm{pH} 4$ by adding formic acid. The extract was added to a WAX cartridge (Oasis WAX $150 \mathrm{mg} 6 \mathrm{cc}$. Waters), washed with ammonium acetate $(\mathrm{pH} 4)$ and tetrahydrofuran (Biosolve)/methanol (3/1), and the analyte eluted with methanol $0.1 \%$ ammonium hydroxide. The eluate was evaporated to dryness and reconstituted in $40 \%$ methanol in ammonium acetate $(2 \mathrm{mM})$.

Plasma and lung lavage

The procedure for extraction of plasma samples followed published method (Yeung et al. 2009) with some modifications. Briefly, $10 \mu \mathrm{L}$ of mass-labelled internal standard was spiked in to the $50 \mu \mathrm{L}$ diluted plasma samples (in MilliQ water); they were mixed with $1 \mathrm{~mL}$ of $0.5 \mathrm{M}$ TBA solution in a $15 \mathrm{~mL}$ PP tube. After mixing, $5 \mathrm{~mL}$ of MTBE was added, and the mixture was shaken for $20 \mathrm{~min}$ at $250 \mathrm{rpm}$. The organic and aqueous layers were separated by centrifugation at $3000 \mathrm{rpm}$ for $15 \mathrm{~min}$. The organic layer MTBE (4 $\mathrm{mL}$ ) was transferred to a new PP $15 \mathrm{~mL}$ tube. The extraction was repeated twice with $5 \mathrm{~mL}$ of MTBE was removed each time. The three extracts were combined in the second PP tube. A $1 \mathrm{~mL}$ of methanol was added to the final extract before it was concentrated to $1 \mathrm{~mL}$ under nitrogen. The extract was further concentrated to $200 \mu \mathrm{L}$ in a LC vial, and mass-labelled recovery standards were spiked into the vial. Aqueous ammonium acetate $(2 \mathrm{mM}, 300 \mu \mathrm{L})$ was added to the vial for PFAS analysis using LC-MS/MS.

\section{Tissues}

All tissue samples were homogenized using a Tissue Tearor (BiospecProducts) with tissue ( $1 \mathrm{~g}$ wet weight) and $1 \%$ potassium chloride solution $(0.2 \mathrm{~mL})$; the homogenate was then spiked with $10 \mu \mathrm{L}$ of mass-labelled internal standard before the ion-pairing extraction procedure as described above for the plasma samples.

Extractable organofluorine (EOF) analysis

Plasma and tissue samples taken at $48 \mathrm{~h}$ after exposure were subjected to EOF analysis. Extraction procedure followed the procedure described above with the exception that no mass labelled internal standards were spiked to the samples before extraction. The EOF content of the $1 \mathrm{~mL}$ extract was analyzed by combustion ion chromatography (CIC). Part of the extract $(200 \mu \mathrm{L})$ was transferred to a LC 
vial with the addition of $10 \mu \mathrm{L}$ of mass-labelled standards; after that aqueous ammonium acetate $(2 \mathrm{mM}$, $300 \mu \mathrm{L}$ ) was added to the vial for PFAS analysis using LC-MS/MS. The reported EOF concentrations as well as the concentration of PFOA for mass balance analysis were not recovery-corrected.

Instrumental analysis of PFOA

PFOA was analyzed using a Waters Acquity UPLC coupled to a Waters Xevo TQ-S triple quadrupole mass spectrometer operating in negative ion mode for electrospray ionization. A Waters Acquity UPLC BEH C18 column $\left(1.7 \mu \mathrm{m}, 50 \times 2.1 \mathrm{~mm}\right.$, Waters) was heated to $50^{\circ} \mathrm{C}$ with a flow rate of $0.5 \mathrm{~mL} / \mathrm{min}$. A $10 \mu \mathrm{L}$ extract aliquot was injected onto the column with mobile phases consisting of $2 \mathrm{mmol} / \mathrm{L}$ ammonium acetate in a mixture of $\mathrm{MeOH}$ and water $\mathrm{MeOH} 30 / 70(\mathrm{v} / \mathrm{v})(\mathrm{A})$ and $2 \mathrm{mmol} / \mathrm{L}$ ammonium acetate in $\mathrm{MeOH}(\mathrm{B})$. Details of the LC-MS method are presented elsewhere (Aro et al., 2021).

Instrumental analysis of extractable organic fluorine (EOF)

Levels of EOF in the sample extracts were determined with a combustion ion chromatography (CIC) system consisting of a combustion module (Analytik Jena, Germany), a 920 Absorber Module and a 930 Compact IC Flex ion chromatograph module (both from Metrohm, Switzerland). An ion exchange column (Metrosep A Supp 5 - 150/4.0), with carbonate buffer $(64 \mathrm{mmol} / \mathrm{L}$ sodium carbonate and $20 \mathrm{mmol} / \mathrm{L}$ sodium bicarbonate) as the mobile phase, were used for the separation of anions; the absorber solution was water. The sample extract $(100 \mu \mathrm{L})$ was set on a silica boat via an autosampler and placed into a furnace at $900-1000^{\circ} \mathrm{C}$. The combustion of the sample in the furnace converted organic fluorine and inorganic fluorine into hydrogen fluoride (HF), which was then trapped by MilliQ water. The fluoride concentration in the solution was analyzed using ion chromatography. A five-point calibration curve at 50, $100,200,500$ and $1000 \mathrm{ng} / \mathrm{mL}$ PFOS standards was constructed using the combustion method as samples and exhibited good linearity with $\mathrm{R}^{2}>0.9999$. Quantification was based on external calibration. The analytical conditions for ion chromatography have been reported elsewhere (Kärrman et al. et al., 2021).

Mass balance analysis approach

The measured PFOA concentration $(\mathrm{ng} / \mathrm{mL})$ in the sample extract of the EOF analysis were converted to the corresponding fluoride-equivalent concentration $(\mathrm{ng} \mathrm{F} / \mathrm{mL})$ using the following formula:

\section{CF_PFAS $=$ CPFAS * NF * AF/MWPFAS (1)}

where CPFAS is the concentration of the target compound (i.e., PFOA), NF is the number of fluorine atoms in the target compound (i.e., 15), AF is the atomic weight of fluorine ( $\mathrm{g} / \mathrm{mol}$, i.e., 19) and MWPFAS is the molecular weight of the target compound (i.e., 413). The sum of known extractable fluorine concentration ( $\left.\Sigma C F \_P F A S\right)$ was calculated by summing the fluorine concentrations from all individual PFASs. Values below limits of quantification (LOQ) were set for calculating $\Sigma$ CF_PFAS. Levels of unidentified organic 
fluorine were calculated by subtracting EOF from all quantifiable PFAS, which in this present study only PFOA.

Quality assurance and quality control (QA/QC)

In PFOA analysis, the method detection limits (MDLs) were determined as three times the signal in the negative control; and in absence of the analyte in the blank the lowest point in the calibration curve, which ranged $0.02-0.04 \mathrm{ng} / \mathrm{mL}$ for most of the PFOA. To ensure stable sensitivity over the entire instrumental analysis a quality assurance (QA) sample made of PFOA standards (2 $\mathrm{ng} / \mathrm{mL})$ was injected between each eight samples; the relative standard deviation of the intensity of QA samples was found to be below $10 \%$. Before real sample analysis, matrix spike recoveries were conducted by spiking $1 \mathrm{ng}$ of PFOA into different tissues (e.g. plasma, liver, lung, lung lavage and kidney) of the control subjects, the accuracy of the method was evaluated by subtracting the spiked level from the non-spiked sample and then divided by the spiked level times 100\%; results were found to be between 92 to $111 \%$ (Table S1, Supplementary Information).

For the analysis of EOF, multiple measurements of combustion blanks were effectuated and repeated until the combustion blanks showed low variability (below $5 \%$ relative standard deviation) over the last three combustion blanks, so as to reduce the CIC system contained background fluoride contamination. All measurements of samples were first subtracted from the combustion blanks between samples before quantification, using an external calibration curve. An instrumental standard (PFOS $480 \mathrm{ng} \mathrm{F/mL}$ ) was analyzed to evaluate the whole performance of the CIC. Signal fluctuation (RSD: 15\%) was observed in the instrument standard in every five samples. A spiked plasma sample containing $200 \mathrm{ng} \mathrm{F} / \mathrm{mL}$ was extracted in triplicate and the recovery were found to be $80 \pm 9 \%$ and the relative standard deviation was found to be $8 \%$.

\section{Results}

Vapor concentration of PFOA

The vapor concentration of PFOA (Cpfoa) measured at the outlet of the vapor pressure generation chamber is described in detail in Sypplementary Information and shown in Figure S1. These measurements were made after 1, 3, 12, 24 and $48 \mathrm{hrs}$ at room temperature. Prior calculations showed that a complete evaporation of the coating (a few grams) at the designated emission rates would suffice for the duration of the test $(48 \mathrm{~h})$ based on the vapor pressure of PFOA. A stable vapor concentration indicating saturation was established already after $24 \mathrm{~h}$ at a concentration of $13.7 \times 10^{-6}(\mu \mathrm{g} / \mathrm{L}$ ) (Figure $\mathrm{S1}$ ), and this is the point we used as reference time point in the adsorption of PFOA on the dust (see next section).

Sorption of PFOA on house dust 
After equilibrating in a near saturated vapor of PFOA for more than 3 weeks, the house dust reached a steady state concentration of PFOA of $0.335 \mathrm{~g} / \mathrm{g}$ coated dust (Figure 1). This likely represents both a smaller fraction of true surface adsorbate and a dominating fraction of absorbed PFOA, dissolved in the more or less liquid constituents of the dust. In addition, some PFOA may have formed condensate in the porous structures of the dust. If the surface adsorbate of monomolecular PFOA has about the same surface density as for aromatic hydrocarbons, or $0.0004 \mathrm{~g} / \mathrm{m}^{2}$ (Gerde et al. 2001), the fully coated BET surface area of the dust of $2.5 \mathrm{~m}^{2} / \mathrm{g}$ would correspond to a dust concentration of only $0.001 \mathrm{~g} / \mathrm{g}$. Therefore, the dust content of PFOA is likely dominated by absorbed fractions and capillary condensates.

Aerosol generation and inhalation exposures

For the inhalation exposures of the rat, an aerosol of house dust was generated, with a MMAD and GSD of $3.7 \mu \mathrm{m}$ and 2.3, respectively, as published in our previous study (Gustafsson et al. 2018). The intratracheally intubated lungs of the four rats were exposed to reach an inhaled mass of $0.51 \pm 0.03 \mathrm{mg}$ of aerosolized house dust according to the real time dose counter of the Preciselnhale system. The aerosol concentration during the exposure cycles ranged between $0.25-0.35 \mathrm{mg} / \mathrm{L}$ (Figure 2). The aerosol was delivered to each exposed rat during 20-25 min, requiring 9-10 reloading's of house dust in order to reach the desired deposited mass of $0.26 \pm 0.01 \mathrm{mg}$ (Figure 2).

Delivered dose of PFOA

The dose of PFOA was calculated based on the mass of PFOA coated on the house dust (335 $\mathrm{mg}$ PFOA/g dust) and the deposited dose administrated to each group. The deposited dose following inhalation or oral gavage of dust resulted in a PFOA dose of $164 \mu \mathrm{g} \mathrm{PFOA} / \mathrm{kg}$ BW and $364 \mu \mathrm{g} \mathrm{PFOA} / \mathrm{kg}$ $B W$, respectively.

PFOA in plasma samples

Both the inhalation- and gavage groups showed a rapid increase of PFOA concentrations in plasma following exposure (Figure 3). The $C_{\max }$ occurred at $3 \mathrm{~h}$ post exposure with a value of $3.10 \pm 0.32 \mathrm{ng} / \mu \mathrm{L}$ in the inhalation group $(n=4)$ and $1.73 \pm 0.17 \mathrm{ng} / \mu \mathrm{L}$ in the oral gavage group $(n=4)$ In the group that received dust by inhalation, the concentration of PFOA decreased at 6 and $24 \mathrm{~h}$ post exposure, followed by a steady state at $48 \mathrm{~h}$ post exposure (Figure 3). For the group that received dust by gavage there was an increase of PFOA in plasma until $3 \mathrm{~h}$ post exposure followed by a steady state of the concentration of PFOA in plasma for the remaining sampling times at 6, 24 and $48 \mathrm{~h}$ post exposure (Figure 3 ).

PFOA in lung lavage, terminal plasma and tissues

The concentrations of PFOA were measured at $48 \mathrm{~h}$ after dust exposure in lung lavage, lung tissue, liver and kidney (Table 1A ). For the group receiving PFOA by inhalation, the largest proportion of PFOA was measured in the lung tissue $(31.3 \pm 4.00 \mu \mathrm{g} / \mathrm{g})$ followed by the liver $(10.1 \pm 0.88 \mu \mathrm{g} / \mathrm{g})$, lung lavage $(9.98$ $\pm 0.63 \mathrm{ng} / \mu \mathrm{l})$ and kidney $(3.84 \pm 0.76 \mu \mathrm{g} / \mathrm{g})$. For the group receiving PFOA by gavage the largest 
proportion was measured in the liver $(8.94 \pm 0.50 \mu \mathrm{g} / \mathrm{g})$, followed by the kidney $(3.15 \pm 0.19 \mu \mathrm{g} / \mathrm{g})$, lung $(1.68 \pm 0.31 \mu \mathrm{g} / \mathrm{g})$ and lung lavage $(0.31 \pm 0.02 \mathrm{ng} / \mu \mathrm{l})$. Similar concentrations of PFOA were measured in plasma for inhalation- and gavage exposures with concentrations of $2.03 \pm 0.32 \mathrm{ng} / \mu \mathrm{L}$ and $1.87 \pm 0.35$ $\mathrm{ng} / \mu \mathrm{L}$, respectively (Table 1 ).

Table 1

Mean PFOA and PFOA-fluorine equivalent concentrations ( $\mathrm{ng} / \mu \mathrm{l} \mathrm{F}$ or $\mu \mathrm{g} / \mathrm{g} \mathrm{F}$ ) of measured PFOA and extractable organic fluorine (EOF) in terminal plasma, lung lavage and organs sample.

\begin{tabular}{|c|c|c|c|c|c|c|c|c|}
\hline \multirow[t]{2}{*}{ Matrix } & \multicolumn{2}{|l|}{$\mathrm{PFOA}^{1}$} & \multicolumn{2}{|c|}{$\begin{array}{l}\text { PFOA-fluorine } \\
\text { equivalent }{ }^{2}\end{array}$} & \multicolumn{2}{|l|}{ EOF $^{2}$} & \multicolumn{2}{|c|}{$\begin{array}{l}\text { Contribution to } \\
\text { EOF (\%) }\end{array}$} \\
\hline & Inhalation & Oral & Inhalation & Oral & Inhalation & Oral & Inhalation & Oral \\
\hline Plasma & $\begin{array}{l}1.97 \pm \\
0.32\end{array}$ & $\begin{array}{l}1.87 \pm \\
0.35\end{array}$ & $\begin{array}{l}1.53 \\
\pm 0.17\end{array}$ & $\begin{array}{l}1.42 \\
\pm 0.24\end{array}$ & $\begin{array}{l}2.15 \\
\pm 0.03\end{array}$ & $\begin{array}{l}2.18 \\
\pm 0.13\end{array}$ & 71 & 65 \\
\hline $\begin{array}{l}\text { Lung } \\
\text { Lavage }\end{array}$ & $\begin{array}{l}9.98 \pm \\
0.63\end{array}$ & $\begin{array}{l}0.31 \pm \\
0.02\end{array}$ & $\begin{array}{l}6.87 \pm \\
0.43\end{array}$ & $\begin{array}{l}0.21 \pm \\
0.02\end{array}$ & $\begin{array}{l}9.01 \pm \\
0.67\end{array}$ & $\begin{array}{l}0.25 \pm \\
0.02\end{array}$ & 76 & 84 \\
\hline Liver & $10.1 \pm 0.9$ & $\begin{array}{l}8.94 \pm \\
0.5\end{array}$ & $\begin{array}{l}6.95 \pm \\
0.65\end{array}$ & $\begin{array}{l}6.14 \pm \\
0.34\end{array}$ & $\begin{array}{l}7.97 \pm \\
0.69\end{array}$ & $\begin{array}{l}7.36 \pm \\
0.36\end{array}$ & 87 & 83 \\
\hline Lung & $31.3 \pm 4.0$ & $\begin{array}{l}1.68 \pm \\
0.3\end{array}$ & $\begin{array}{l}21.5 \pm \\
2.75\end{array}$ & $\begin{array}{l}1.16 \pm \\
0.21\end{array}$ & $\begin{array}{l}24.9 \pm \\
2.76\end{array}$ & $\begin{array}{l}1.55 \pm \\
0.28\end{array}$ & 86 & 74 \\
\hline Kidney & $3.84 \pm 0.8$ & $\begin{array}{l}3.15 \pm \\
0.2\end{array}$ & $\begin{array}{l}2.64 \pm \\
0.53\end{array}$ & $\begin{array}{l}2.16 \pm \\
0.13\end{array}$ & $\begin{array}{l}3.26 \pm \\
0.65\end{array}$ & $\begin{array}{l}2.63 \pm \\
0.18\end{array}$ & 81 & 83 \\
\hline \multicolumn{9}{|c|}{${ }^{1}$ Concentration is present in $\mathrm{ng} / \mu \mathrm{l}$ for plasma and lung lavage and $\mu \mathrm{g} / \mathrm{g}$ for organ samples } \\
\hline
\end{tabular}

Extractable organic fluorine (EOF)

Plasma and tissues samples taken at $48 \mathrm{~h}$ after exposure showed detectable EOF concentrations (Table 1). For inhalation exposure, the amount of EOF in descending order was lung, lung lavage, liver, kidney and plasma samples. As for oral gavage, the trend was different from the inhalation exposure with the greatest amount of EOF was detected in the liver, followed by kidney/plasma, lung and lung lavage samples. These trends were also different from target PFOA analysis for both inhalation and oral exposures.

In general, PFOA accounted for over $80 \%$ of the EOF in all tissue samples with the exception of plasma samples in the two exposure groups (Table 1). The proportion of PFOA to EOF in plasma samples were lower (around $68 \%$ for inhalation and $64 \%$ for oral exposure). Mass balance analysis between EOF and target PFOA in these samples indicated the occurrence of potential PFAS metabolites formed by other unknown PFAS precursor and/or other fluorinated compounds that co-existed in the dust samples.

\section{Discussion}


This is, to the best of our knowledge, the first study to measure the bioavailability of PFOA over the lungs following an inhalation exposure to house dust. PFOA were adsorbed onto a respirable fraction of house dust collected from residential homes. The use of the Preciselnhale ${ }^{\circledR}$ system proved to be an efficient way of delivering aerosolized house dust to the lung of rats, realistically mimicking dust inhalation exposures and lung deposition. In this study, we compared the bioavailability of PFOA following an inhalation exposure with an oral exposure of dust delivered via gavage. This study reveals that the bioavailability of PFOA over the lung is almost four times higher in blood, at 3 hours post exposure, compared to the oral gavage exposure.

Hinderliter and co-workers exposed rats via inhalation to PFOA administrated as an aerosolized solution. During the 6 hours exposure, the concentration of PFOA in plasma rose proportional $(1-25 \mu \mathrm{g} / \mathrm{mL})$ to the exposure concentration (1-25 mg/m $\mathrm{m}^{3}$ ). The $\mathrm{C}_{\max }$ of PFOA in plasma appeared between $0-6$ hours post the six-hour exposure (Hinderliter et al. 2006). In our study, the $C_{\max }$ of PFOA occurred between 0-3 hours post exposure after which the levels of PFOA in plasma started to decline until 24 hours post exposure, a time point where it reached a steady state until the end of the experiment. Hinderliter and co-workers also studied sex differences. The elimination of PFOA in females was rapid; hence at the end of the 6-h exposure time the levels in plasma were almost twice as high in male compared to the females. The fast elimination in female continued post exposure and was almost complete unlike in males where the elimination of PFOA was slow (Hinderliter et al. 2006). This is in line with the present results, where the plasma concentration in the male rats indicated a slow excretion rate during the $48 \mathrm{~h}$ after exposure. There is a large species dependent difference in elimination rate of PFOA where rats have a half-time of a few days compared to humans having a calculated half-time of 2.3-8.5 years (Li et al. 2017). In humans, the long half-time might be associated with a short-term high exposure level of PFOA, while the 8.5 year half-time might be associated with a chronic low exposure to PFOA as well as transformation of other PFOA precursors (Seals et al. 2011). In humans, only a slight difference in elimination rate of PFOA between the sexes has been observed. These observations were made in humans exposed to drinking water contaminated with PFAS (Li et al, 2018).

The mechanisms for the bioaccessibility and bioavailability of inhaled SVOCs are complex and have recently been described in (Wei et al. 2018 and Wei et al. 2020). With bioaccessibility we here refer to the fraction of a compound that is released into the body fluid and is available for absorption (Caboche et al., 2011; Collins et al., 2015; Rostami and Juhasz, 2011; Wei et al. 2018). While we define the bioavailability as the amount that can reach the systemic circulation by crossing the pertinent biological membranes (Collins et al., 2015; Rostami and Juhasz, 2011; Yu et al., 2012; Wei et al. 2018). The results from Hinderliter and colleges indicates that the bioavailability of PFOA over the air-blood barrier is high. Comparing the bioavailability of PFOA exposed either via inhalation as wet aerosol or adsorbed onto particles should imply a simpler mechanism of bioavailability of PFOA delivered as wet aerosol. In our study the high concentrations of PFOA in the lung tissue and lung lavage indicated that dust-associated and/or desorbed PFOA still remained in the lung compartment at 48 hours after exposure. 
Previous studies have showed that the bioavailability of PFOA and PFOA ammonium salt following an oral exposure is almost complete (DeWitt 2015, kap. 6 and references therein; Hundley et al. 2006). Our result indicate that initially within the first three hours post exposure there is a higher concentration in plasma from rats that received PFOA via inhalation compared to oral gavage exposure. At 48 hours after exposure, compared to inhalation exposures, the concentration in plasma following oral gavage was similar, although the delivered dose of PFOA was 2.2 times higher. Regarding organ distribution of PFOA post exposure, there is an almost 2.5 times higher distribution of PFOA to the liver and kidney following inhalation exposures compared to oral gavage. Following an oral exposure, bioavailable substances enter the liver directly via the portal vein. Previous studies have shown that PFOA binds to proteins in blood (Beesoon and Martin, 2015; Butenhoff et al. 2012; Forsthuber et al. 2020) and more than 90\% of PFOA was typically determined to be bound to albumin in serum (Han et al, 2003). A study on oral exposure to PFOA in rats, showed that the tissue distribution was highest in the liver (Kim et al. 2016). The tissue distribution of radiolabelled PFOA $\left({ }^{14} \mathrm{C}\right.$-PFOA $)$ in mice following a dietary exposure showed that concentrations were highest in the liver, followed by blood, lungs and kidneys (Bogdanska et al. 2020). The present study demonstrated that following oral exposure, the highest concentrations of PFOA were found in the liver, followed by kidneys, lungs (lung + lung lavage) and blood.

The disposition of PFOA following exposures differ between rats and humans. In rats, the main distribution of PFOA is to blood, liver and kidney of which female rats distributed higher levels of PFOA to the kidney compared to male rats (DeWitt. 2015). In humans, the distribution of PFOA in the body occurred primarily to bone followed by lung, liver and kidney (Pérez et al. 2013). Maestri and colleagues detected the highest levels in lung, kidney, liver, and blood; while the neuro system had the lowest levels (Maestri et al. 2006). Since PFOA is not subjected to biotransformation or metabolism in the body, the major elimination route is via excretion (DeWitt. 2015; Stahl et al. 2011).

Overall, most results in the literature show that the major source of exposure to PFOA is via food (Haug 2011a; Poothong et al. 2020; Sunderland et al. 2019; Trudel et al. 2008). However, Haug and colleagues also showed that a large variation in serum concentrations may be related to indoor contamination, because only a smaller variation of the dietary intake in the study group was found. The indoor environment contributed to more than $40 \%$ of the PFOA exposure for some people in the study group (Haug et al. 2011a). The indoor environment can be an important factor when characterizing human exposure to PFAS like PFOA (Haug et al 2011a).

In a previous study we estimated that the deposited mass of house dust following inhalation is relatively low $(0.03 \mathrm{mg} / 24 \mathrm{~h}$ in children and $0.07 \mathrm{mg} / 24 \mathrm{~h}$ in adults) (Gustafsson et al. 2021 manuscript in preparation). Yet the low deposition of dust in the airways is of concern since PFOA are persistent and bioaccumulative.

The absorption kinetics in the lungs for indoor air pollutants has not been subjected to extensive research. In this study we used house dust, a common occurrence in indoor environments, as a matrix for exposure to air pollution. Chemicals with the property of being SVOCs adsorb to surfaces of particulates,

Page $13 / 25$ 
hence house dust may serve as a sink for environmental indoor pollutants (Butte et al. 2002). Previous studies have demonstrated a large spectrum of environmental air pollutants adsorbed to the surface of house dust, including flame-retardants, plasticizers, antioxidants, and PFAS (Eriksson and Kärrman, 2015; Mercier et al. 2011; Weschler and Nazaroff, 2008). There are scarce experimental data regarding the physicochemical properties of PFAS. The vapor pressure for the PFAS family varies greatly between substances, some of which are within the range of SVOC (Eichler and Little 2020). Evidently, both the predicted and measured vapor pressure of PFOA exceeds the upper range of what is defined as SVOCs (Eichler and Little 2020). Nevertheless, several studies provide ample evidence of PFAS presence on house dust from the indoor environment (Eriksson and Kärrman, 2015; Weiss et al, 2021; Winken et al. 2017; Yao et al. 2018). Eriksson and Kärrman (2015) also detected the presence of different classes of PFAS in house dust, and one single group of compounds was measured in levels up to $\mu \mathrm{g} / \mathrm{g}$ (Eriksson and Kärrman, 2015). In the current investigation, the measured PFOA concentrations explained a majority $(65-87 \%)$ of the EOF levels in the samples, suggesting that PFOA was the major PFAS coated onto the dust. It should be noted that the imbalance in the ratio of PFOA to EOF in the samples implies the presence of unidentified organic fluorine compounds which might be the results of the following scenarios: 1) the dust samples might contain some precursor compounds that can have been metabolized into unknown intermediates; for examples polyfluoroalkyl phosphate esters (PAPs), a known PFCA precursors that were shown to form PFCAs with a number of unknown degradation intermediates; 2) there were other unidentified PFAS already present in the dust samples, and 3) the PFOA compound might have formed some unknown conjugated products. However, the identification and possible accumulation patterns of such unknown organic fluorine compounds are out of the scope of the present work.

In this study, we chose to intubate the rats and deliver the dust directly to the lungs by using the intratracheal inhalation module of the Preciselnhale platform. In this way, we avoided the typical high deposition of such aerosols in the nasal airways that otherwise would have occurred if the more common choice of the nose-only inhalation module had been selected. Bypassing the nasal airways in rodents using intratracheal inhalation is a particular advantage when dealing with aerosols, as in this case, having MMADs toward the upper limit of the respirable interval. From the MPPD aerosol deposition software it can be calculated that if the same lung-deposited dose in rats would have been required using the nose-only module, $75 \%$ would have been caught in the nasal airways, leaving only $25 \%$ in the target area of the lower respiratory tract. Another advantage of using intratracheal exposures is the avoidance of a dominating fraction of inhaled dust initially depositing in the nose, but subsequently redistributing to the gastro-intestinal tract by mucociliary clearence. Because of the high aerosol concentration during the inhalation exposures, it is likely that the dominating fraction of PFOA remained on the particulate fraction instead of desorbing to the gas phase. Another advantage with the high dose rate is that even a dose target of $0.5 \mathrm{mg}$ particles inhaled can be reached in approximately $20 \mathrm{~min}$, which is a particular advantage during kinetic studies. The active dosing mechanism of the Preciselnhale helps to keep the standard deviation between repeated exposures generally below $\pm 10-15 \%$ (Figure 2). The house dust spiked with PFOA represents another complex powder substrate that can be prepared and aerosolized for 
small scale inhalation exposures using the Dustgun generator of the Preciselnhale ${ }^{\circledR}$ platform. Previously, powders such as diesel soot, silica dust, and palladium nanoparticles have been generated into respirable aerosols (Ewing et al. 2006; Gerde et al. 2004; Wilkinson et al. 2011).

In conclusion, we demonstrated that there is a fast absorption over the airways to the systemic circulation of dust-associated PFOA, following inhalation exposures to house dust. The concentration of PFOA in plasma is approximately four times higher compared to the same deposition level of exposure via oral gavage. The ubiquitous presence of PFOA in indoor environment and exposures of humans is of concern, due to the long half-times of duration in humans. Several endocrine related effects have been shown following exposure to PFOA, and important target tissues are mammary gland, thyroid and adipose tissue (DeWitt 2015). It is known that PFOA pass the placenta into the fetal circulation (DeWitt 2015). At the stage of development from infant to the prepubertal period there are key moments in development that are sensitive to chemicals, which may cause long term effects (Birnbaum and Fenton 2003). The observations presented in this manuscript emphasize house dust as a potentially important matrix of exposure to indoor pollution. The investigation of indoor pollutant bioavailability, via either inhalation-, oral- or skin absorption is largely unexplored and requires further research.

\section{Declarations}

\section{Acknowledgements}

The authors acknowledge Marie Eriksson, Camilla Bengtsson, Jenny Lindahl, Josephine Hjoberg, Bo Watz, Björn Platzack and Johan Lindberg at RISE for animal experimental performance. Ewa Selg at Inhalation Sciences for scientific advice following aerosolization with the Preciselnhale system. Swedish Research Council Formas for the financial support. Authors from ORU acknowledged the Knowledge Foundation (KKS) for funding the project within the Enforce Research Profile (20160019), Sweden.

\section{Funding}

The Swedish Research Council Formas. Dnr 216-2013-1966. Authors from ORU acknowledged the Knowledge Foundation (KKS) for funding the project within the Enforce Research Profile (20160019), Sweden.

\section{Author information}

Affiliations

MTM Research Centre. School of Science and Technology, Örebro University, SE-701 82 Örebro, Sweden Bei Wang, Åke Bergman, Leo W.Y. Yeung and Åsa Gustafsson Institute of Environmental Medicine, Karolinska Institutet, Stockholm, SE-171 77 Sweden 
Inhalation Sciences AB, Hälsovägen 7-9, SE-141 57 Huddinge, Sweden

Per Gerde

Department of Environmental Science, Stockholm University, SE-10691 Stockholm, Sweden

Åke Bergman

\section{Contributions}

BW, PG and $\AA$ G prepared the PFOA adsorbed dust. $\AA$ G, PG and $\AA$ B planned the animal study. BW performed the chemical analyses under supervision of $L Y$ and $\AA \mathrm{B}$. All authors contributed to and approved the final manuscript.

\section{Ethics declarations}

Ethics approval and consent to participate

The study was performed after permission from the Swedish Board of Agriculture and Linköping Ethical Committee on Animal Studies (No. 31-10466/12).

\section{Consent for publication}

Not applicable.

\section{Competing interests}

The authors declare no competing interests.

\section{References}

1. Aro R, Eriksson U, Kärrman A, Yeung LWY (2021) Organofluorine Mass Balance Analysis of Whole Blood Samples in Relation to Gender and Age. Environ Sci Technol. 55. pp. 13142-13151

2. Asgharian BF, Miller O, Price F, Cassee J, Freijer, Bree L (2002) Multiple Path Particle Deposition Model (MPPD). A model for human and rat airway particle deposition. Bilthoven. The Netherlands. National Institute for Public Health and the Environment (RIVM)

3. Awad R, Zhou Y, Nyberg E, Namazkar S, Yongning W, Xiao Q, Sun Y, Zhu Z, Bergman Ã, Benskin JP (2020). Emerging per- and polyfluoroalkyl substances (PFAS) in human milk from Sweden and China. Environ Sci Process Impacts. Oct 1;22(10):2023-2030. doi: 10.1039/d0em00077a. Epub 2020 Sep 17. Erratum in: Environ Sci Process Impacts. 2021 Feb 4;23(1):188. PMID: 32940316

4. Beesoon S, Martin JW (2015) Isomer-Specific Binding Affinity of Perfluorooctanesulfonate (PFOS) and Perfluorooctanoate (PFOA) to Serum Proteins. Environ Sci Technol. May 5;49(9):5722-31. doi: 10.1021/es505399w. Epub 2015 Apr 13. PMID: 25826685 
5. Birnbaum LS, Fenton SE (2003) Cancer and developmental exposure to endocrine disruptors. Environ Health Perspect 111:389-394

6. Björklund JA, Thuresson K, de Wit CA (2009) Perfluoroalkyl compounds (PFAS) in indoor dust: concentrations, human exposure estimates, and sources. Environ Sci Technol. 43. pp. 2276-2281

7. Bogdanska J, Borg D, Bergström U, Mellring M, Bergman Ã, DePierre J, Nobel S (2020) Tissue distribution of 14C-labelled perfluorooctanoic acid in adult mice after 1-5 days of dietary exposure to an experimental dose or a lower dose that resulted in blood levels similar to those detected in exposed humans. Chemosphere Jan 239:124755. doi: 10.1016/j.chemosphere.2019.124755. Epub 2019 Sep 4. PMID: 31726523

8. Buck RC, Franklin J, Berger U, Conder JM, Cousins IT, de Voogt P, Astrup Jensen A, Kannan K, Mabury SA, van Leeuwen SP (2011) Perfluoroalkyl and Polyfluoroalkyl Substances in the Environment: Terminology, Classification, and Origins. Integr Environ Assess Manag 7(4):513-541

9. Butenhoff JL, Pieterman E, Ehresman DJ, Gorman GS, Olsen GW, Chang SC, Princen HM (2012) Distribution of perfluorooctanesulfonate and perfluorooctanoate into human plasma lipoprotein fractions. Toxicol Lett. May 5;210(3):360-5. doi: 10.1016/j.toxlet.2012.02.013. Epub 2012 Feb 24. PMID: 22387339

10. Butte W, Heinzow B (2002) Pollutants in house dust as indicators of indoor contamination. Rev Environ Contam Toxicol 175:1-46. PMID: 12206053.

11. Byrne S, Seguinot-Medina S, Miller P, Waghiyi V, von Hippel FA, Buck CL, Carpenter DO (2017) Exposure to polybrominated diphenyl ethers and perfluoroalkyl substances in a remote population of Alaska Natives. Environ Pollut Dec; 231(Pt 1):387-395. doi: 10.1016/j.envpol.2017.08.020. Epub 2017 Aug 17

12. Caboche J, Perdrix E, Malet B, Alleman LY (2011) Development of an in vitro method to estimate lung bioaccessibility of metals from atmospheric particles. J Environ Monit 13:621-630. 10.1039/c0em00439a

13. Calafat AM, Wong LY, Kuklenyik Z, Reidy JA, Needham LL Polyfluoroalkyl chemicals in the U.S. population: data from the National Health and Nutrition Examination Survey (NHANES) 2003-2004 and comparisons with NHANES 1999-2000.Environ Health Perspect. 2007Nov;115(11):1596-602. doi: 10.1289/ehp.10598. PMID: 18007991; PMCID: PMC2072821.

14. Collins CD, Craggs M, Garcia-Alcega S, Kademoglou K, Lowe S (2015) Towards a unified approach for the determination of the bioaccessibility of organic pollutants'. Environ Int May 78:24-31. doi: 10.1016/j.envint.2015.02.005. Epub 2015 Feb 27. PMID: 25728561

15. De Silva AO, Armitage JM, Bruton TA, Dassuncao C, Heiger-Bernays W, Hu XC, Kärrman A, Kelly B, Ng C, Robuck A, Sun M, Webster TF, Sunderland EM PFAS Exposure Pathways for Humans and Wildlife: A Synthesis of Current Knowledge and Key Gaps in Understanding.Environ Toxicol Chem. 2021Mar; 40(3):631-657. doi: 10.1002/etc.4935. Epub 2021 Jan 29. PMID: 33201517; PMCID: PMC7906948.

16. DeWitt JC, Blossom SJ, Schaider LA (2019) Exposure to per-fluoroalkyl and polyfluoroalkyl substances leads to immunotoxicity: epidemiological and toxicological evidence. J Expo Sci Environ 
Epidemiol 29(2):148-156. doi: 10.1038/s41370-018-0097-y. Epub 2018 Nov 27

17. DeWitt (2015) Toxicological Effects of Perfluoroalkyl and Polyfluoroalkyl Substances. Springer, Cham Heidelberg New York Dordrecht London. DOI 10.1007/978-3-319-15518-0

18. D'Hollander W, Roosens L, Covaci A, Cornelis C, Reynders H, Campenhout KV, Voogt Pd, Bervoets L (2010) Brominated flame retardants and perfluorinated compounds in indoor dust from homes and offices in Flanders. Belgium Chemosphere 81(4):478-487.. doi:

10.1016/j.chemosphere.2010.07.043. Epub 2010 Aug 14.

19. Egeghy P, Lorber M (2011) An assessment of the exposure of Americans to perfluorooctane sulfonate: a comparison of estimated intake with values inferred from the NHANES data. J Expo Sci Environ Epidemiol 21:150-168

20. Eichler CMA, Little JC (2020) A framework to model exposure to per- and polyfluoroalkyl substances in indoor environments. Environ Sci Process Impacts. 1;22(3):500-511. doi: 10.1039/c9em00556k. Epub 2020 Mar 6. PMID: 32141451

21. Eriksson U, Kärrman A (2015) World-wide indoor exposure to polyfluoroalkyl phosphate esters (PAPs) and other PFASs in household dust. Environ Sci Technol 49:14503-14511. doi: 10.1021/acs.est.5b00679

22. Ewing P, Blomgren B, Ryrfeldt A, Gerde P (2006) Increasing Exposure Levels Cause an Abrupt Change in the Absorption and Metabolism of Acutely Inhaled Benzo(a)pyrene in the Isolated. Ventilated. and Perfused Lung of the Rat. Toxicol Sci 91(2):332-340

23. Forsthuber M, Kaiser AM, Granitzer S, HassI I, Hengstschläger M, Stangl H, Gundacker C (2020) Albumin is the major carrier protein for PFOS, PFOA, PFHxS, PFNA and PFDA in human plasma. Environ Int 137:105324. doi: 10.1016/j.envint.2019.105324. Epub 2020 Feb 25. PMID: 32109724

24. Gerde P, Ewing P, Låstbom L, Ryrfeldt A, Waher J, Lidén G (2004) A novel method to aerosolize powder for short inhalation exposures at high concentrations: isolated rat lungs exposed to respirable diesel soot. Inhal Toxicol. Jan;16(1):45-52. doi: 10.1080/08958370490258381. PMID: 14744664

25. Gerde P, Muggenburg BA, Lundborg M, Dahl AR (2001) The rapid alveolar absorption of diesel sootadsorbed benzo[a]pyrene: bioavailability, metabolism and dosimetry of an inhaled particle-borne carcinogen. Carcinogenesis. 22(5):741-9. doi: 10.1093/carcin/22.5.741. PMID: 11323393

26. Goosey E, Harrad S (2011) Perfluoroalkyl compounds in dust from Asian. Australian. European. and North American homes and UK cars. classrooms. and offices. Environ Int 37(1):86-92

27. Han X, Snow TA, Kemper RA, Jepson GW (2003) Binding of perfluorooctanoic acid to rat and human plasma proteins. Chem Res Toxicol. 16(6):775-81. doi: 10.1021/tx034005w. PMID: 12807361

28. Haug LS, Huber S, Becher G, Thomsen C (2011a) Characterisation of human exposure pathways to perfluorinated compounds-comparing exposure estimates with biomarkers of exposure. Environ Int 37(4):687-693. doi: 10.1016/j.envint.2011.01.011. Epub 2011 Feb 18. PMID: 21334069

29. Haug LS, Huber S, Schlabach. M, Becher. G, Thomsen C (2011b) Investigation on per and polyfluorinated compounds in paired samples of house dust and indoor air from Norwegian homes. 
Environ Sci Technol 45:7991-7998

30. Hinderliter PM, DeLorme MP, Kennedy GL (2006) Perfluoroctanoic acid: Relationship between repeated inhalation exposures and plasma PFOA concentrations in the rat. Toxicology 222:80-85

31. Hu XC, Tokranov AK, Liddie J, Zhang X, Grandjean P, Hart JE, Laden F, Sun Q, Yeung LWY, Sunderland EM (2019 Jun) Tap Water Contributions to Plasma Concentrations of Poly- and Perfluoroalkyl Substances (PFAS) in a Nationwide Prospective Cohort of U.S. Women. Environ Health Perspect 127(6):67006.. doi: 10.1289/EHP4093. Epub 2019 Jun 6. PMID: 31170009; PMCID: PMC6792361.

32. Huber S, Haug LS, Schlabach M (2011) Per- and polyfluorinated compounds in house dust and indoor air from northern Norway-a pilot study. Chemosphere 84:1686-1693. doi:

10.1016/j.chemosphere.2011.04.075

33. Hundley SG, Sarrif AM, Kennedy GL (2006) Absorption, distribution, and excretion of ammonium perfluorooctanoate (APFO) after oral administration to various species. Drug Chem Toxicol 29:137145

34. Kato K, Calafat AM, Needham LL (2009) Polyfluoroalkyl chemicals in house dust. Environ Res 109:518-523

35. Kärrman A, Yeung LWY, Spaan KM, Lange FT, Nguyen MA, Plassmann M, de Wit CA, Scheurer M, Awad R, Benskin JP (2021) Can determination of extractable organofluorine (EOF) be standardized? First interlaboratory comparisons of EOF and fluorine mass balance in sludge and water matrices. Environ Sci Process Impacts 23:1458-1465

36. Kim SJ, Heo SH, Lee DS, Hwang IG, Lee YB, Cho HY (2016) Gender differences in pharmacokinetics and tissue distribution of 3 perfluoroalkyl and polyfluoroalkyl substances in rats. Food Chem Toxicol 97:243-255. doi: 10.1016/j.fct.2016.09.017. Epub 2016 Sep 13. PMID: 27637925

37. Koch A, Kärrman A, Yeung LWY, Jonsson M, Ahrens L, Wang T (2019) Point source characterization of per- and polyfluoroalkyl substances (PFASs) and extractable organofluorine (EOF) in freshwater and aquatic invertebrates. Environ Sci Process Impacts. 1;21(11):1887-1898. doi:

10.1039/c9em00281b. Epub 2019 Sep 25. PMID: 31552402

38. Knobeloch L, Imm P, Anderson H (2012) Perfluoroalkyl chemicals in vacuum cleaner dust from 39 Wisconsin homes. Chemosphere 88(7):779-783. doi: 10.1016/j.chemosphere.2012.03.082. Epub 2012 Apr 27

39. Kubwabo C, Stewart B, Zhu J, Marro L (2005) Occurrence of perfluorosulfonates and other perfluorochemicals in dust from selected homes in the city of Ottawa. Canada. J Environ Monit 7:1074-1078

40. Li Y, Fletcher T, Mucs D, Scott K, Lindh CH, Tallving P, Jakobsson K (2018) Half-lives of PFOS, PFHxS and PFOA after end of exposure to contaminated drinking water. Occup Environ Med 75(1):46-51. doi: 10.1136/oemed-2017-104651. Epub 2017 Nov 13. PMID: 29133598; PMCID: PMC5749314

41. Li K, Gao P, Xiang P, Zhang X, Cui X, Ma LQ (2017) Molecular mechanisms of PFOA-induced toxicity in animals and humans: Implications for health risks. Environ Int 99:43-54 
42. Maestri L, Negri S, Ferrari M, Ghittori S, Fabris F, Danesino P, Imbriani M (2006) Determination of perfluorooctanoic acid and perfluorooctanesulfonate in human tissues by liquid chromatography/single quadrupole mass spectrometry. Rapid Commun Mass Spectrom 20:27282734

43. Malmlöf M, Nowenwik M, Meelich K, Radberg I, Selg E, Burns J, Mascher H, Gerde P (2019) "Effect of particle deposition density of dry powders on the results produced by an in vitro test system simulating dissolution- and absorption rates in the lungs". Eur J Pharm Biopharm 139:213-223

44. Marple VA, McCormack JE (1983) Personal sampling impactor with respirable aerosol penetration characteristics. Am Ind Hyg Assoc J 44(12):916-922

45. Mercier F, Glorennec P, Thomas O, Bot BL (2011) Organic contamination of settled house dust, a review for exposure assessment purposes. Environ Sci Technol 45(16):6716-6727. DOI:

$10.1021 /$ es200925h

46. Moriwaki H, Takata Y, Arakawa R (2003) Concentrations of perfluorooctane sulfonate (PFOS) and perfluorooctanoic acid (PFOA) in vacuum cleaner dust collected in Japanese homes. J Environ Monit 5(5):753-757

47. Moss OR, James RA, Asgharian B (2006) Influence of exhaled air on inhalation exposure delivered through a directed-flow nose-only exposure system. Inhal Toxicol 18(1):45-51

48. OECD (2018) Toward A New Comprehensive Global Database of Per- and Polyfluoroalkyl Substances (PFASs): Summary Report on Updating the OECD 2007 List of Per- and Polyfluoroalkyl Substances (PFASs); OECD Series on Risk Management; OECD: Paris, 2018; Vol. 39, p 24

49. Pérez F, Nadal M, Navarro-Ortega A, Fàbrega F, Domingo JL, Barceló D, Farré M (2013) Accumulation of perfluoroalkyl substances in human tissues. Environ. Int.. 59. pp. 354-362

50. Poothong S, Papadopoulou E, Padilla-Sánchez JA, Thomsen C, Haug LS (2020) Multiple pathways of human exposure to poly- and perfluoroalkyl substances (PFASs): From external exposure to human blood. Environ Int 134:105244. doi: 10.1016/j.envint.2019.105244. Epub 2019 Nov 8. PMID: 31711019

51. Rostami I, Juhasz AL (2011) Assessment of persistent organic pollutant (POP) bioavailability and bioaccessibility for human health exposure assessment: a critical review Crit. Rev Environ Sci Technol 41.. 623-656, 10.1080/10643380903044178

52. Sadia M, Yeung LWY, Fiedler H (2020) Trace level analyses of selected perfluoroalkyl acids in food: Method development and data generation. Environ Pollut. Aug;263(Pt A):113721. doi:

10.1016/j.envpol.2019.113721. Epub 2019 Dec 17. PMID: 32229370

53. Salthammer T, Zhang Y, Mo J, Koch HM, Weschler CJ (2018) Assessing human exposure to organic pollutants in the indoor environment. Angew Chem Int Ed 57:12228-12263

54. Seals R, Bartell SM, Steenland K (2011) Accumulation and clearance of perfluorooctanoic acid (PFOA) in current and former residents of an exposed community. Environ. Health Perspect.. 119. p. 119 
55. Selg E, Acevedo F, Nybom R, Blomgren B, Ryrfeldt A, Gerde P (2010) Delivering horseradish peroxidase as a respirable powder to the isolated, perfused, and ventilated lung of the rat: the pulmonary disposition of an inhaled model biopharmaceutical. J Aerosol Med Pulm Drug Deliv 26(4):181-189. doi: 10.1089/jamp.2012.0971

56. Selg E, Ewing P, Acevedo F, Sjöberg CO, Ryrfeldt A, Gerde P (2013) Dry powder inhalation exposures of the endotracheally intubated rat lung, ex vivo and in vivo: the pulmonary pharmacokinetics of fluticasone furoate. J Aerosol Med Pulm Drug Deliv 26(4):181-189. doi: 10.1089/jamp.2012.0971

57. Stahl T, Mattern D, Brunn H (2011) Toxicology of perfluorinated compounds. Environmental Sciences Europe 23(38):1-52

58. Sunderland EM, Hu XC, Dassuncao C, Tokranov AK, Wagner CC, Allen JG (2019 Mar) A review of the pathways of human exposure to poly- and perfluoroalkyl substances (PFASs) and present understanding of health effects. J Expo Sci Environ Epidemiol 29(2):131-147. doi: 10.1038/s41370018-0094-1. Epub 2018 Nov 23. PMID: 30470793; PMCID: PMC6380916

59. Tao L, Kannan K, Wong CM, Arcaro KF, Butenhoff JL Perfluorinated compounds in human milk from Massachusetts, U.S.A. Environ Sci Technol. 2008 Apr 15;42(8):3096-101. doi: 10.1021/es702789k. PMID: 18497172

60. Tian Z, Kim SK, Shoeib M, Oh JE, Park JE (2016) Human exposure to per- and polyfluoroalkyl substances (PFASs) via house dust in Korea: Implication to exposure pathway. Sci Total Environ 15:553:266-275. doi: 10.1016/j.scitotenv.2016.02.087. Epub 2016 Feb 28

61. Trudel D, Horowitz L, Wormuth M, Scheringer M, Cousins IT, Hungerbuhler K (2008) Estimating consumer exposure to PFOS and PFOA. Risk Anal. 2008. 28 (3). 807-807

62. Verner MA, Loccisano AE, Morken NH, Yoon M, Wu H, McDougall R, Maisonet M, Marcus M, Kishi R, Miyashita C, Chen MH, Hsieh WS, Andersen ME, Clewell HJ 3, Longnecker MP (2015) Associations of Perfluoroalkyl Substances (PFAS) with Lower Birth Weight: An Evaluation of Potential Confounding by Glomerular Filtration Rate Using a Physiologically Based Pharmacokinetic Model (PBPK). Environ Health Perspect 123(12):1317-1324

63. Vierke L, Staude C, Biegel-Engler A, Drost W, Schulte C (2012) Perfluorooctanoic acid (PFOA) - main concerns and regulatory developments in Europe from an environmental point of view. Environmental Sciences Europe 24:16

64. Völkel W, Genzel-Boroviczény O, Demmelmair H, Gebauer C, Koletzko B, Twardella D, Raab U, Fromme H Perfluorooctane sulphonate (PFOS) and perfluorooctanoic acid (PFOA) in human breast milk: results of a pilot study. Int J Hyg Environ Health. 2008 Jul;211(3-4):440-6. doi: 10.1016/j.ijheh.2007.07.024. Epub 2007 Sep 17. PMID: 17870667

65. Wang Z, DeWitt JC, Higgins CP, Cousins IT (2017) A Never-Ending Story of Per- and Polyfluoroalkyl Substances (PFASs)? Environ Sci Technol. 7;51(5):2508-2518. doi: 10.1021/acs.est.6b04806. Epub 2017 Feb 22

66. Wei W, Bonvallot N, Gustafsson Ã, Raffy G, Glorennec P, Krais A, Ramalho O, Le Bot B, Mandin C (2018) Bioaccessibility and bioavailability of environmental semi-volatile organic compounds via 
inhalation: A review of methods and models. Environ Int 2018 Apr 113:202-213. doi:

10.1016/j.envint.2018.01.024. Epub 2018 Feb 13. PMID: 29448239

67. Wei W, Ramalho O, Mandin C (2020) Modeling the bioaccessibility of inhaled semivolatile organic compounds in the human respiratory tract. Int J Hyg Environ Health 224:113436. doi:

10.1016/j.ijheh.2019.113436. Epub 2019 Dec 21. PMID: 31978732

68. Weschler CJ, Nazaroff WW (2008) Semivolatile organic compounds in indoor environments. Atmos Environ 42:9018-9040

69. Weiss JM, Jones B, Koekkoek J, Bignert A, Lamoree MH (2021) Per- and polyfluoroalkyl substances (PFASs) in Swedish household dust and exposure of pet cats. Environ Sci Pollut Res Int. $2021 \mathrm{Mar}$ 20. doi: 10.1007/s11356-021-13343-5. Epub ahead of print. PMID: 33745045

70. Wilkinson KE, Palmberg L, Witasp E, Kupczyk M, Feliu N, Gerde P, Seisenbaeva GA, Fadeel B, Dahlen SE, Kessler VG (2011) Solution-Engineered Palladium Nanoparticles: Model for Health Effect Studies of Automotive Particulate Pollution. ACS Nano 26;5((7):5312-5324. doi: 10.1021/nn1032664. Epub 2011 Jun 13. PMID: 21650217

71. Winkens K, Giovanoulis G, Koponen J, Vestergren R, Berger U, Karvonen AM, Pekkanen J, Kiviranta H, Cousinsa I (2018) Perfluoroalkyl acids and their precursors in floor dust of children's bedrooms Implications for indoor exposure.Environment International:119. Pp.493-502

72. Xu Z, Fiedler S, Pfister G, Henkelmann B, Mosch C, Völkel W, Fromme H, Schramm KW (2013) Human exposure to fluorotelomer alcohols. perfluorooctane sulfonate and perfluorooctanoate via house dust in Bavaria. Germany Sci Total Environ 443(0):485-490. http://dx.doi.org.proxy.kib.ki.se/ 10.1016/j.scitotenv.2012.10.089

73. Ye X, Kato K, Wong LY, Jia T, Kalathil A, Latremouille J, Calafat AM (2018) Per- and polyfluoroalkyl substances in sera from children 3 to 11 years of age participating in the National Health and Nutrition Examination Survey 2013-2014. Int J Hyg Environ Health 221(1):9-16. doi:10.1016/j.ijheh.2017.09.01

74. Yao Y, Zhao Y, Sun H, Chang S, Zhu L, Alder AC, Kannan K (2018) Per- and Polyfuoroalkyl Substances (PFASs) in Indoor Air and Dust from Homes and Various Microenvironments in China: Implications for Human Exposure. Environ Sci Technol 52:3156-3166

75. Yu YX, Pang YP, Li C, Li JL, Zhang XY, Yu ZQ, Feng JL, Wu MH, Sheng GY, Fu JM (2012) Concentrations and seasonal variations of polybrominated diphenyl ethers (PBDEs) in in- and outhouse dust and human daily intake via dust ingestion corrected with bioaccessibility of PBDEs. Environ Int 42:124-131. doi: 10.1016/j.envint.2011.05.012. Epub 2011 Jun 22. PMID: 21696827

\section{Figures}




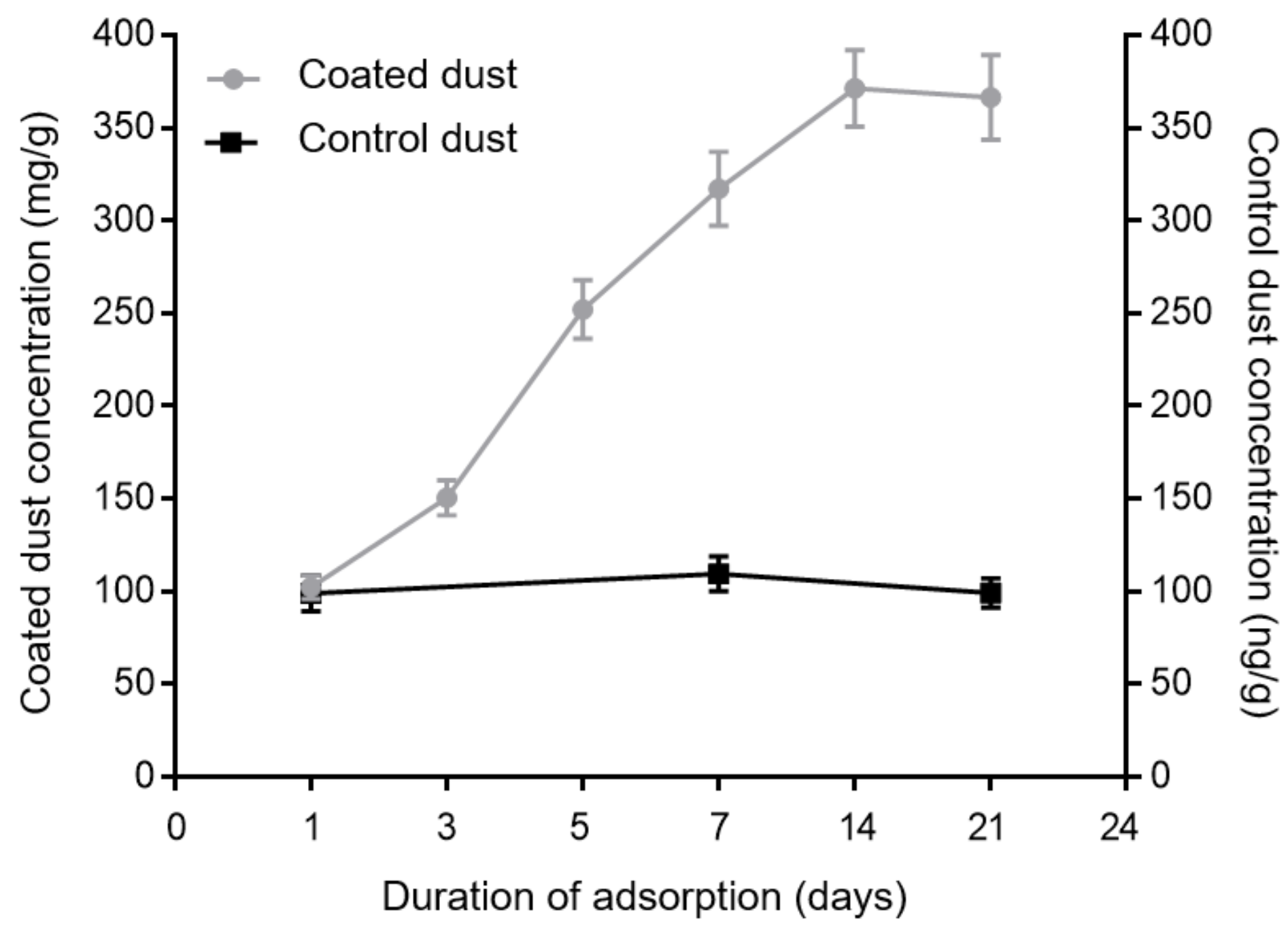

Figure 1

The concentrations of reference-coated dust throughout the whole dust coated experiment and homogeneity sample analyses between replicated adsorption experiments $(n=3)$ 


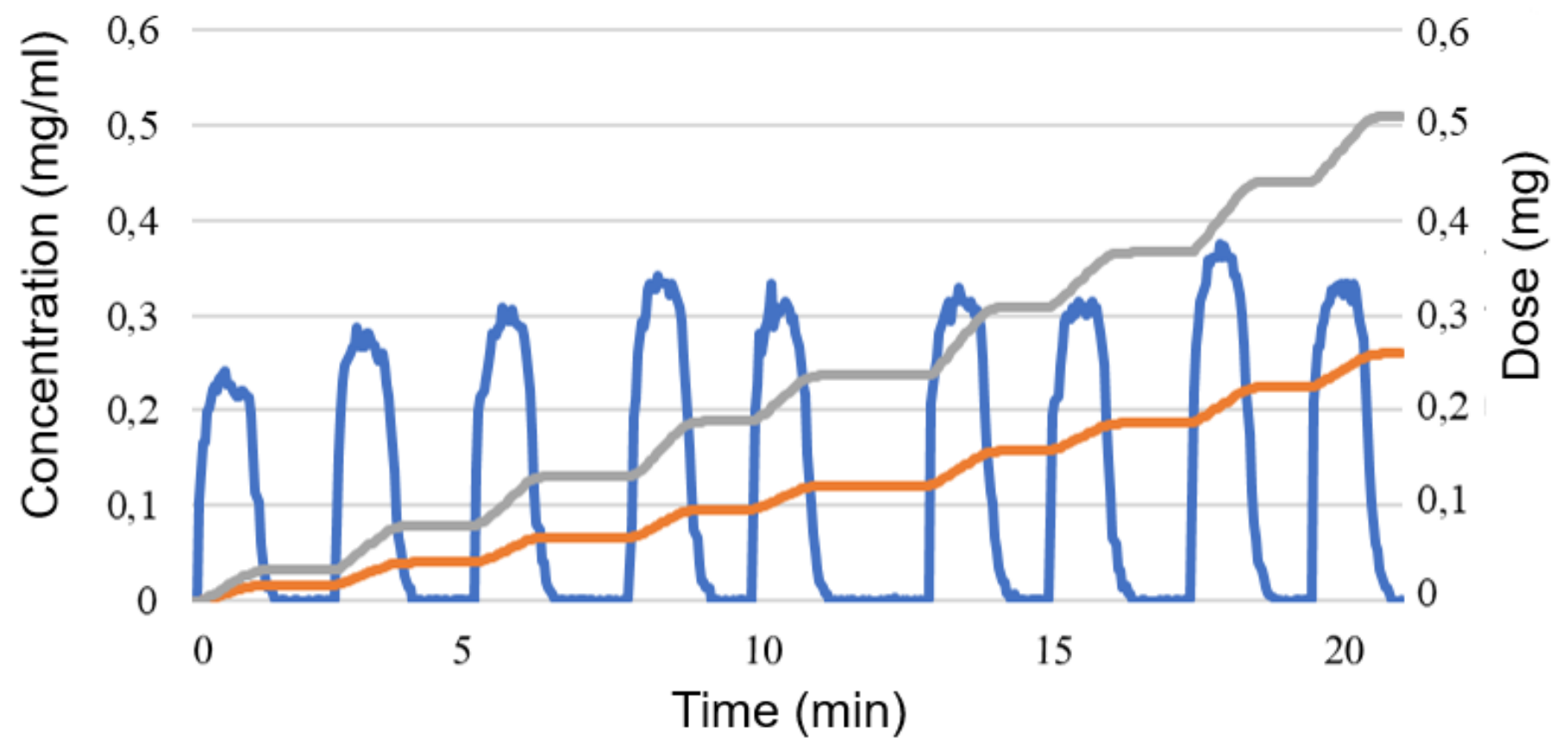

Conc. $(\mathrm{mg} / \mathrm{L}) \longrightarrow$ Deposited dose $(\mathrm{mg}) —$ Inhaled dose $(\mathrm{mg})$

\section{Figure 2}

The aerosol concentration and accumulated inhaled dose of house dust in one of the intratracheally intubated rats. The exposure required 9 consecutive aerosol generation cycles of the Preciselnhale system. The displayed dose is the cumulative value of filter corrected aerosol concentration times the tidal volume as calculated by the Preciselnhale control program. 


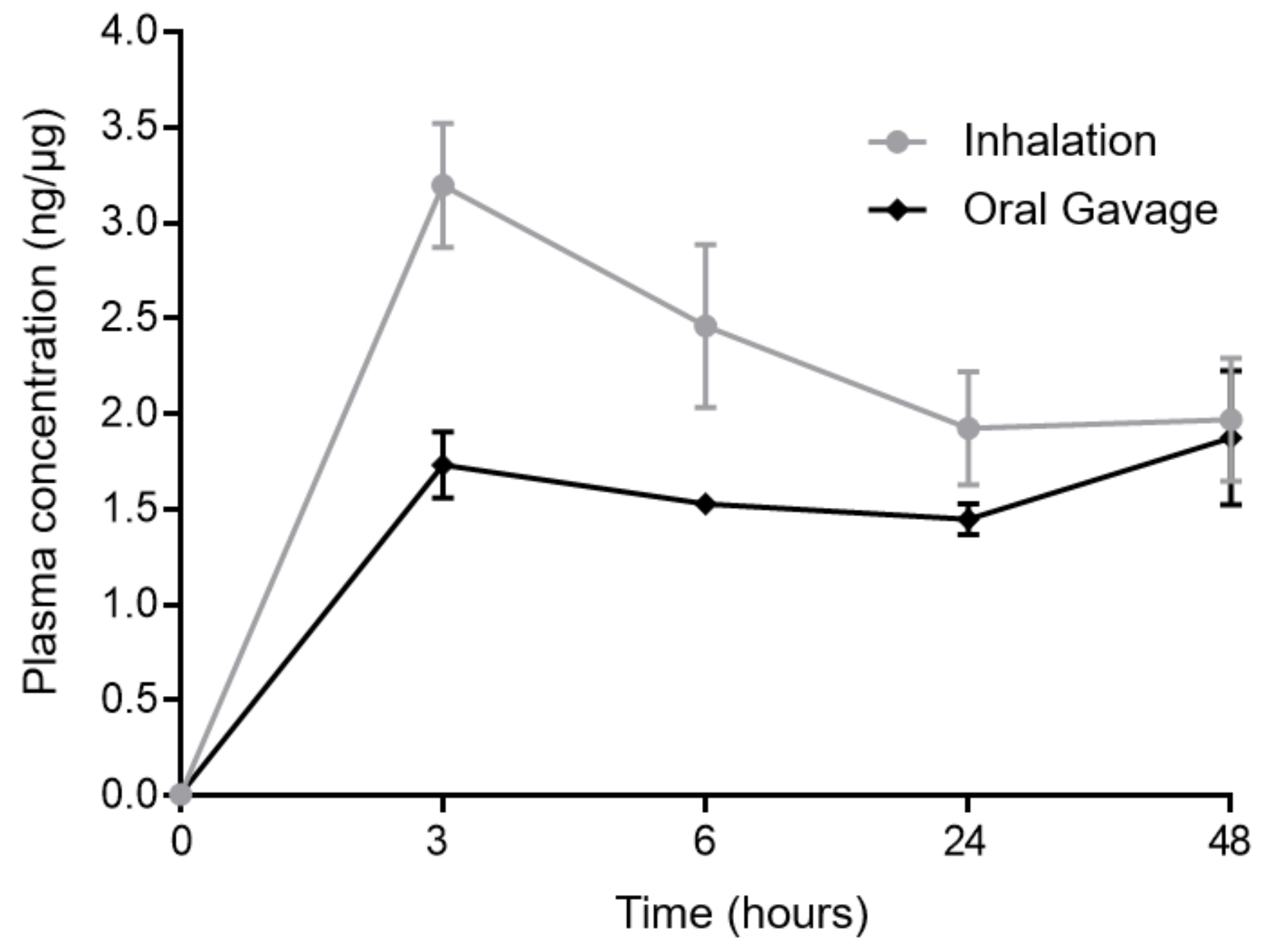

Figure 3

Concentration $(\mathrm{ng} / \mu \mathrm{l})$ of PFOA over time in plasma from rats following inhalation and gavage administration of house dust coated with PFOA $(n=4)$. At time zero the level of PFOA was $0.01 \pm 0.002$ $\mathrm{ng} / \mu \mathrm{l}(\mathrm{n}=10)$.

\section{Supplementary Files}

This is a list of supplementary files associated with this preprint. Click to download.

- Supplementary.docx 